\title{
DESAIN ANTENA Wi-Fi DENGAN MEDIA SENG
}

\author{
Eka Wahyudi ${ }^{1}$, Adnan Purwanto ${ }^{2}$, Teguh Iklas $\mathbf{M}^{3}$ \\ ${ }^{1,2,3}$ Program Studi Diploma III Teknik Telekomunikasi, Purwokerto \\ 1ekawahyudi@gmail.com, ${ }^{2}$ mc_pwt@yahoo.com, ${ }^{3}$ ti_miranto@yahoo.co.id
}

\begin{abstract}
ABSTRAK
Teknologi Internet berbasis Wi-Fi dibuat dan dikembangkan di Amerika Serikat yaitu oleh Institute of Electrical and Electronis Engineers (IEEE) yang berdasarkan kelompok standar teknis perangkat bernomor IEEE 802.11. Perangkat Wi-Fi sebenarnya tidak hanya mampu bekerja di jaringan Wireless Local Area Network (WLAN), tetapi juga di jaringan Wireless Metropolitan Area Network (WMAN). Kuantitas pengguna Internet berbasis teknologi Wi-Fi yang semakin meningkat di berbagai belahan dunia, telah mendorong internet service providers (ISP) untuk membangun hotspot yang di berbagai kota-kota besar. Hotspot merupakan suatu tempat dimana tersedianya koneksi jaringan di mana para pemakai dapat melakukan akses Internet dengan cara nirkabel (wireless) tanpa tergantung kepada jaringan fisik. Jangkauan hotspot dapat dimaksimalkan dengan memanfaatkan antena dengan desain khusus sehingga cakupan (coverage) pancaran sinyal lebih luas. Proses pembuatan desain antena dengan media seng yang diaplikasikan untuk hotspot Wi-Fi pada outdoor diawali dengan perhitungan link budget, antara lain gain dan beamwidth dari antena. Proses pengukuran sinyal diukur dengan menggunakan bantuan software NetStumbler.
\end{abstract}

Kata Kunci: Antena, Wi-Fi, hotspot, seng, IEEE 802.11

\section{PENDAHULUAN}

Penggunaan teknologi berbasis Wi-Fi saat ini sedang pesat dikalangan pengguna internet. Secara teknis operasional, Wi-Fi adalah suatu standar wireless networking tnpa kabel, hanya dengan komponen yang sesuai dapat terkoneksi ke jaringan. Teknologi Wi-Fi memiliki standar yang ditetapkan oleh sebuah institusi internasional yang bernama IEEE, beberapa standar tersebut antara lain sebagai berikut :

1.Standar IEEE 802.11a yaitu Wi-Fi dengan frekuensi $5 \mathrm{GHz}$ yang memiliki kecepatan 54 Mbps dan jangkauan jaringan $75 \mathrm{~m}$

2.Standar IEEE 802.11 b yaitu Wi-Fi dengan frekuensi 2,4 GHz yang memiliki kecepatan 11 Mbps dan jangkauan jaringan $100 \mathrm{~m}$

3.Standar IEEE 802.11g yaitu Wi-Fi dengan frekuensi 2,4 GHz yang memiliki kecepatan 54 Mbps dan jangkauan jaringan $75 \mathrm{~m}$

Tingginya animo masyarakat, khususnya di kalangan komunitas internet menggunakan teknologi Wi-Fi dikarenakan paling tidak dua faktor Tingginya animo masyarakat, khususnya di kalangan komunitas internet menggunakan teknologi Wi-Fi dikarenakan paling tidak dua faktor. pertama, kemudahan akses. Artinya, para pengguna dalam satu area dapat mengakses internet secara bersamaan tanpa perlu direpotkan dengan kabel. Konsekuensinya, pengguna yang ingin melakukan surfing atau browsing berita dan informasi di internet, cukup membawa pocket digital assistance (PDA) atau laptop berkemampuan Wi-Fi ke tempat dimana terdapat access point atau hotspot.

Keinginan para pengguna hotspot dapat sangat bervariasi sesuai dengan lingkungan sekitarnya. Sebagai contoh, para penguna dari kalangan industri atau perdagangan akan memiliki tingkat keinginan/kebutuhan yang berbeda dengan pengguna yang berada di café. Orang yang bepergian untuk berbisnis tinggal di hotel yang dapat menggunakan hotspot akan 
memiliki keinginan yang berbeda juga. Jika keinginan para pengguna tidak dapat dimengerti sepenuhnya, maka kesuksesan dari hotspot akan sangat dipertanyakan. Agar pelayanan yang diperoleh oleh pelanggan dapat maksimal, perlu dilakukan perencanaan yang baik sebelum hotspot ini diimplementasikan. Saat ini kendala yang muncul adalah faktor biaya yang dapat dijangkau oleh para pengguna $W i-F i$ sehingga bisa mendapatkan koneksi internet dilihat dari sisi antenna.

\section{METODOLOGI PENELITIAN}

Dalam jurnal ini akan dibuat sebuah antenna yang dipergunakan untuk hotspot di wilayah kampus atau pendidikan. Instrumen penelitian dalam pembuatan antenna ini terdiri dari beberapa komponen antara lain:

a. Seng dengan panjang $20 \mathrm{~cm}$ dan diametrer $10 \mathrm{~cm}$.

b. USB kabel konektor.

c. Wireless LAN card.

Sedangkan untuk melengkapi data-data yang diperlukan (data sekunder) maka penulis berusaha mencari bahan-bahan dari literatur yang berkaitan dengan antenna. Rancangan dalam pembuatan antenna untuk aplikasi hotspot dapat digambarkan dalam flow chart berikut:

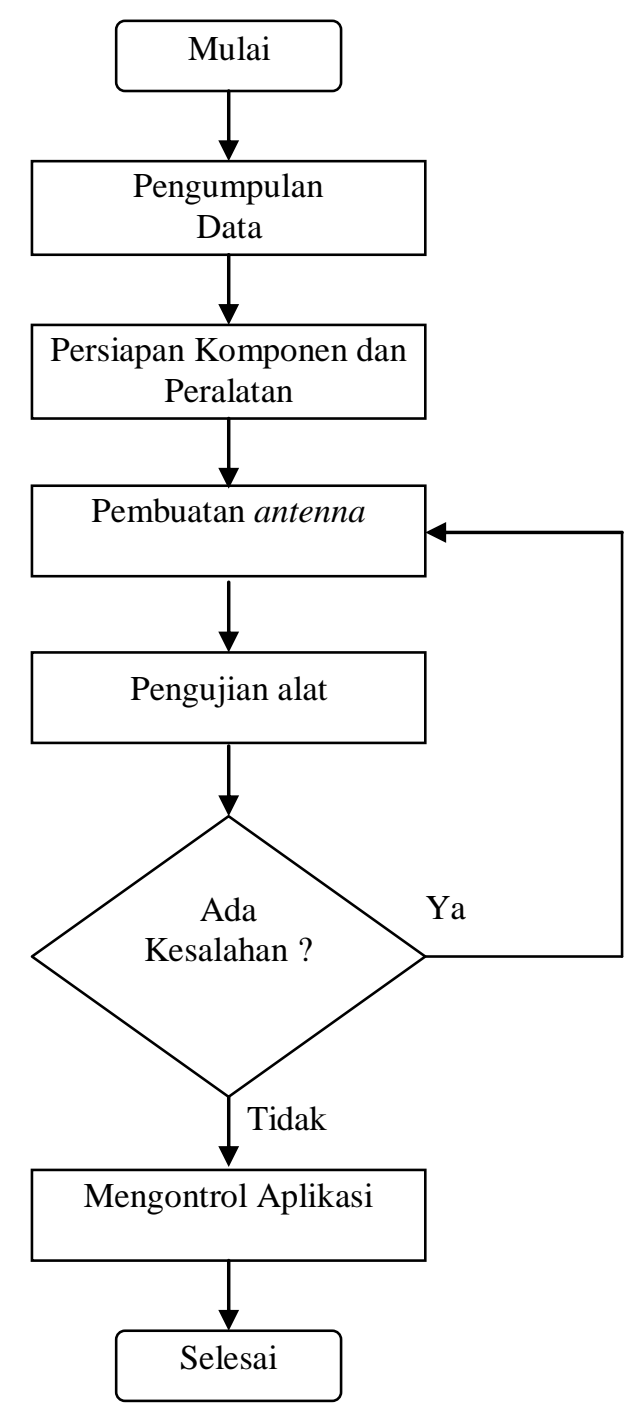

Gambar 1. Flow Chart Rancangan Pembuatan Antenna

Untuk tahap pengujian maka pengukuran signal strength menggunakan NetStumbler.

\section{HASIL DAN PEMBAHASAN}

Antenna adalah susunan seperangkat peralatan yang dikondisikan energi gelombang elektromagnetik dari medium fisik ke medium ruang bebas/free space. Dengan kata lain antenna berfungsi sebagai interface/antarmuka dari dua media pengirim informasi yang berbeda. 


\section{A. Cara Pembuatan Antenna Dengan Media}

\section{Seng}

1 Memilih kaleng (seng) dengan profil dimensi yang sesuai dalam jurnal ini yakni kaleng dengan diameter $10 \mathrm{~cm}$ dan panjang $20 \mathrm{~cm}$.

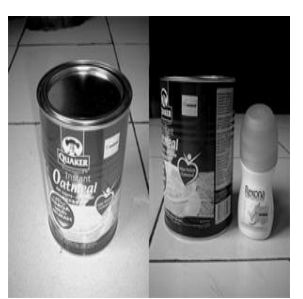

Gambar 2. Kaleng sebagai bahan pembuatan antenna

2 Membersihkan seng (kaleng) dan meratakannya.

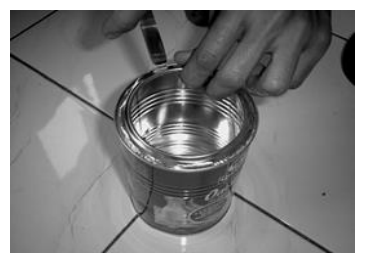

Gambar 3. Membersihkan seng (kaleng) dan meratakannya

3 Mengukur profil diameter dan panjang kaleng

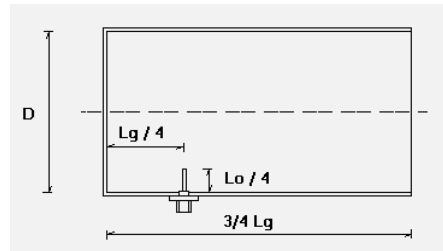

Gambar 4. Mengukur titik wavegiude

4 Menentukan titik waveguide dari dasar antenna

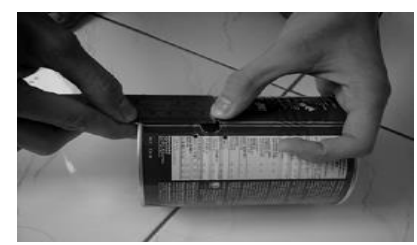

Gambar 5. Mengukur titik wavegiude
5 Melubangi titik wave guide dengan persamaan:

a. $\mathrm{Lg} / 4 \quad$ : Diameter kaleng (seng)

b. Lo/4 : Panjang kaleng (seng)
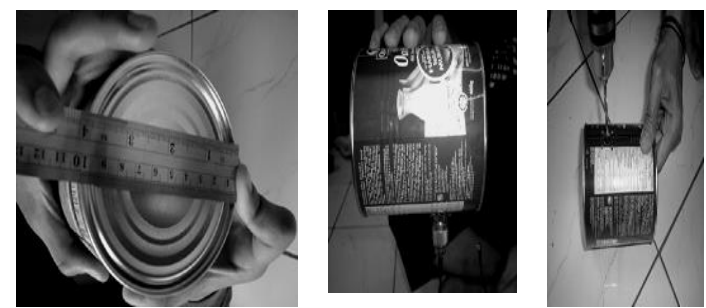

Gambar 6. Memasang kabel konektor

6. Memasang Wireless LAN card.

7. Menyiapkan pipa untuk pengaman kabel.

8. Menguji antenna menggunakan software

NetStumbler.

\section{B. Hasil Perhitungan Antenna Dengan Media} Seng

\section{Gain Antenna}

$G=10 \log$ Eff $+20 \log f+20 \log D+20,4$

dengan $\quad \mathrm{G}: \quad$ Gain antenna $(\mathrm{dB})$

Eff: Efisiensi

f : $\quad$ frekuensi $(\mathrm{GHz})$

D: $\quad$ Diameter $(\mathrm{m})$

Anntena dengan diameter $10 \mathrm{~cm}$ digunakan untuk Wi-Fi 2,4 Ghz dengan efisiensi 0,4 gain yang didapat adalah :

Diameter (d) : $10 \mathrm{~cm}(0,1 \mathrm{~m})$

Frekuensi (f) : 2,4 GHz

Effisiensi : 0,4

$\mathrm{G}=10 \log 0,4+20 \log 2,4+20 \log 0,1+$ $20,4=4,02 \mathrm{~dB}$

\section{Beamwidth}

$$
\mathrm{BW}=\left(\left(3 * 10^{\wedge} 8 / \mathrm{f}\right) * 57,29\right) / \mathrm{D} * \sqrt{\eta}
$$

dengan BW : Beamwidth (deg)

F : frekuensi 


$$
\begin{array}{ll}
\mathrm{D} & : \text { diameter }(\mathrm{m}) \\
\eta & : \text { Effisiensi antenna }(0,4)
\end{array}
$$

Antenna dengan diameter $(\mathrm{d}): 10 \mathrm{~cm}(0,1 \mathrm{~m})$

Frekuensi : 2,4 Ghz $=2,4 * 10^{\wedge} 9 \mathrm{~Hz}$

Effisiensi : 0,4

maka

$\mathrm{BW}=\left(\left(3^{*} 10^{\wedge} 8 / 2,4^{*} 10^{\wedge} 9\right) * 57,29\right) / 0,1^{*} \sqrt{0,4}=$ 45,12 degrees.

\section{Pengolahan Data File Netstumbler}

Data yang perlu ditampilkan pada file NetStumbler ini adalah nilai RSL. Tabel 1 memperlihatkan nilai RSL hasil pengukuran pada beberapa pengamatan.

Tabel 1. Pengukuran Nilai RSL

\begin{tabular}{|c|c|c|c|}
\hline No & $\begin{array}{c}\text { Tempat } \\
\text { Pengukuran }\end{array}$ & $\begin{array}{c}\text { Tanpa } \\
\text { Antenna }\end{array}$ & $\begin{array}{c}\text { Dengan } \\
\text { antenna }\end{array}$ \\
\hline 1 & Lab.TE/TD & $\begin{array}{c}- \\
58(\mathrm{dBM})\end{array}$ & $\begin{array}{c}- \\
55(\mathrm{dBM})\end{array}$ \\
\hline 2 & Lab.Switching & $\begin{array}{c}-65 \\
(\mathrm{dBM})\end{array}$ & $\begin{array}{c}- \\
63(\mathrm{dBM})\end{array}$ \\
\hline 3 & Lab.Komputer 2 & $\begin{array}{c}- \\
63(\mathrm{dBM})\end{array}$ & $60(\mathrm{dBM})$ \\
\hline 4 & Lab.Komputer 1 & - & - \\
$69(\mathrm{dBM})$ & $63(\mathrm{dBM})$ \\
\hline
\end{tabular}

Catatan : Pengukuran dilakukan selama 30 menit , dengan rentang waktu pengambilan setiap 5 menit dan nilainya dirata-ratakan

Tabel 2. Pengukuran Nilai SNR

\begin{tabular}{|c|c|c|c|}
\hline No & $\begin{array}{c}\text { Tempat } \\
\text { Pengukuran }\end{array}$ & $\begin{array}{c}\text { Tanpa } \\
\text { Antenna }\end{array}$ & $\begin{array}{c}\text { Dengan } \\
\text { antenna }\end{array}$ \\
\hline 1 & Lab.TE/TD & $42(\mathrm{dBM})$ & $45(\mathrm{dBM})$ \\
\hline 2 & Lab.Switching & $35(\mathrm{dBM})$ & $37(\mathrm{dBM})$ \\
\hline 3 & Lab.Komputer 2 & $37(\mathrm{dBM})$ & $40(\mathrm{dBM})$ \\
\hline 4 & Lab.Komputer 1 & $31(\mathrm{dBM})$ & $37(\mathrm{dBM})$ \\
\hline
\end{tabular}

Catatan : Pengukuran dilakukan selama 30 menit, dengan rentang waktu pengambilan setiap 5 menit dan nilainya dirata-ratakan

Tabel 3. Nilai Loss

\begin{tabular}{|c|c|c|c|}
\hline No & Tempat & $\begin{array}{c}\text { Nilai loss } \\
\text { tanpa } \\
\text { antenna }\end{array}$ & $\begin{array}{c}\text { Nilai loss } \\
\text { dengan } \\
\text { antenna }\end{array}$ \\
\hline 1 & Lab.TE/TD & $82,02 \mathrm{~dB}$ & $79,02 \mathrm{~dB}$ \\
\hline 2 & Lab.Switching & $89,02 \mathrm{~dB}$ & $87,02 \mathrm{~dB}$ \\
\hline 3 & $\begin{array}{c}\text { Lab.Komputer } \\
2\end{array}$ & $87,02 \mathrm{~dB}$ & $84,02 \mathrm{~dB}$ \\
\hline 4 & $\begin{array}{c}\text { Lab.Komputer } \\
1\end{array}$ & $93,02 \mathrm{~dB}$ & $87,02 \mathrm{~dB}$ \\
\hline
\end{tabular}

Dari data pada tabel 1, tabel 2 dan tabel 3 dapat dianalisa pengaruh antenna pada nilai RSL, SNR dan nilai Loss dapat diamati bahwa pada saat tanpa antenna maka nilai RSL lebih kecil dibanding dengan menggunakan antenna sebagai contoh pada pengukuran di Lab. TE/Td nilai RSL tanpa menggunakan antenna adalah 58 setelah menggunakan antenna maka nilainya -55 ada penambahan -3 , hal ini adanya penguatan pada antenna dari efek material yang digunakan sabagai bahan pembuatan antenna walaupun bertambah nilainya hanya sedikit. Sedangkan untuk nilai SNR dapat diamati sebelum menggunakan antenna pada pengukuran di Lab. TE/TD adalah $42 \mathrm{dBm}$ setelah menggunakan antenna menjadi $45 \mathrm{dBM}$ ada kenaikan $3 \mathrm{dBm}$ dari hasil semula. Untuk nilai SNR selain dari hasil pengukuran dapat juga dengan persamaan teoritis yaitu :

\section{$\mathrm{S} / \mathrm{N}=$ level signal-level noise}

Sebagai contoh pada pengukuran di Lab. TE/TD dimana nilai level signal adalah -58 sedangkan nilai level noise pada pengukuran yaitu konstan -100 sehingga bisa didapat nilai SNR $=-58-(-100)=42 \mathrm{dBm}$, begitu juga 
dengan nilai SNR pada pengukuran di Lab yang lain.

\section{KESIMPULAN}

Dari keseluruhan kegiatan pengukuran yang dilakukan pada jurnal ini, dapat ditarik beberapa kesimpulan sebagai berikut :

1. Cara pembuatan antenna dengan media seng yaitu dengan mempersiapkan beberapa material diantaranya : kaleng (seng) dengan panjang $20 \mathrm{~cm}$ dan diameter $10 \mathrm{~cm}$, USB kabel konektor, Wireless LAN card.

2. Loss penetrasi dinding dan penghalang yang lain sangat berpengaruh terhadap kualitas signal yang didapat oleh antenna dan itu merupakan kunci dari propagasi pada desain antenna ini.

3. Dari hasil pengukuran dan analisa didapatkan bahwa gain sebessar 4,02 dB, dari hasil itu dapat diaplikasikan untuk $W i$ $F i$ dimana nilai gain dari antenna kaleng (media seng) dengan rata-rata 4-6 dB yang disarankan. Beamwidth sebesar 45,12 degrees dengan ini pancaran signal yang didapat akan lebih focus pada antenna dengan media seng yang dibuat

4. Dari hasil pengukuran dan analisa didapatkan bahwa, untuk signal pengukuran dimana nilai RSL dan SNR sebelum menggunakan antenna nilainya kecil setelah menggunakan antenna nilainya bertambah hal ini diakibatkan adanya penguatan pada antenna dari efek material yang digunakan sehingga nilai dari RSL dan SNR bertambah hal ini bisa dilihat pada tabel 1 dan tabel 2, sedangkan untuk nilai loss sebelum adanya antenna nilainya besar kemudian setelah menggunakan antenna nilainya turun hal ini antenna dapat meminimalisir adanya penurunan loss dari perbedaan propagasi pada masing-masing tempat pengukuran hal ini bisa dilihat pada tabel 3 .

\section{DAFTAR PUSTAKA}

1. Arinanto, Kurniawan Dwi. Wardriving Serangan Terhadap Wireless LAN.Tugas Akhir.ITB.Bandung. 2002

2. Freeman, L Rooger. Telecomunicaation Transmission Handbook : Edisi Ke-empat

3. Hammond, John. Wireless Hotspot Deployment Guide : Intel 2001

4. Heriadi, Dodi. Jaringan Wi-Fi Teori dan Implementasi. Yogyakarta : Penerbit Andi

5. Kurniawan, Dian. Perencanaan Hotspot Wi$F i$ di Savoy Homann Bidakara Hotel. Tugas Akhir. STTTelkom.Bandung. 2005

6. Mulyana, Edi. Pengenalan Protokol Jaringan Wireless Komputer. Yogyakarta : Penerbit Andi

7. Purbo, W Onno. Infrastruktur Wireless Internet. Yogyakarta : Penerbit Andi

8. Salahuddien, M. www.Lintaslangit.net/ indek.php.

9. Anonymous, www.Netstumbler.com/ downloads akses tanggal 9 Maret 2007

10. www.turnpoint.net/wireless/cantennahowto .html akses tanggal 24 Maret 2007 